24. On leave at the Howard Hughes Medical Institute Iaboratory and the Department of Medicine, University of California, San Francisco, USA.

25. We are grateful to Dr. Y. W. Kan for his continuing advice and Rita Loi for editorial assistance. Wc would also like to thank Dr. B. Forget for the plasmid JW-10I and Drs. J. Lauer and T. Maniatis for plasmid pBR $\zeta$.

26. Requests for reprints should be addressed to: Professor Antonio Cao, Istituto di Clinica e Biologia dell'Età Evolutiva, Università degli Studi di Cagliari, c/o Ospedale Regionale delie Microcitemie, Via Jenner, (Casella Postale 251),
09100 Cagliari Sardinia, Italy.

27. This work was supported by grants from Assessorato Igiene e Sanità Regione Autonoma della Sardegna (progetio 833). The National Institute of Health (HL-24173-03), Program of Preventive Medicine CNR (Rome, Italy) Project M.E.E. n. 8136.83 and CNR Institute for the Study of Thalassemia and Mediterranean Anemias, Cagliari.

28. Received for publication August 3,1982

29. Accepted for publication March 30, 1983.

\title{
Plasma and Red Blood Cell Fatty Acid Composition in Children with Protein-Calorie Malnutrition
}

\author{
JON A. WOLFF, ${ }^{(4)}$ SIMEON MARGOLIS, KATALIN BUJDOSO-WOLFF, EDWARD MATUSICK. \\ AND WILLIAM C. MACLEAN.JR. \\ Department of International Health. The Johns Hopkins University School of Hygiene and Public Health \\ I. ... H.. K. B. W. Department of Medicine, The Johns Hopkins Lniversity School of Medicine, Baltimore, \\ Maryland /S.M.J: Ross Laboratories Columbus, Ohio: Lipid Laboratory, Beltswille Iuman Nutrition Research \\ Institute, Beltsville, Maryland, USA /W. C.M.I
}

\begin{abstract}
Summary
Plasma and red cell fatty acids were measured in 44 children with third degree malnutrition: 22 children with marasmus, 11 children with kwashiorkor, and 11 with marasmic kwashiorkor (MK). The presence of edema, dermatosis, hair changes, and hypoalbuminemia were positively correlated with the red cell percentage linoleic acid and negatively correlated with red cell percentage arachidonic acid. Red cell percentage linoleic acid in kwashiorkor was decreased from the control value of $15.3 \%$ to $10.9 \%$. In marasmus and MK, there were significantly greater decreases, to $7.7 \%$ and $\mathbf{8 . 0 \%}$, respectively. Red cell arachidonic acid in kwashiorkor was significantly $(P<0.001)$ decreased to $\mathbf{9 . 8 \%}$ (control value of $13.1 \%$ ) whereas in marasmus there was no significant change. Only one sample, plasma from an infant with marasmus, had any detectable eicosatrienoic acid $(20: 3, \omega 9)$. Similar changes in fatty acid composition have been reported in infants with acrodermatitis enteropathica, in an infant with biotin deficiency, and in biotin-deficient rats.
\end{abstract}

\section{Abbreviations}

EFA, essential fatty acid

MK, marasmic kwashiorkor

PCM, protein-calorie malnutrition

RBC, red blood cell

PCM encompasses three clinical syndromes: kwashiorkor, marasmus, and MK. Kwashiorkor is characterized by edema, dermatosis, enlarged fatty liver, changes in hair pigment and texture, and decreased serum albumin in the presence of normal subcutaneous fat. Marasmic infants are generally younger and lack any specific physical or laboratory findings other than wasting of muscles and decreased subcutaneous fat. Many infants with marasmus exhibit some, but not all, of the signs of kwa- shiorkor and are designated MK. The McLaren score has proven useful in differentiating among the three syndromes (25).

The etiology and pathogenesis of the forms of PCM remain unclear. Animals fed a high carbohydrate, low protein diet often develop kwashiorkor. Those on a low carbohydrate, low protein diet exhibit marasmus. Studies comparing the dietary histories of infants with kwashiorkor and marasmus frequently failed to show any such dietary correlation (27). Even so, protein deficiency could explain some of the findings in kwashiorkor. The edema of kwashiorkor results, in part, from the low serum albumin concentration, and the fatty liver is felt to be the result of decreased lipoprotein synthesis $(6,15,22,35,42)$.

The dermatosis of kwashiorkor may be the result of tryptophan deficiency because it resembles the dermatosis in pellagra. Human EFA deficiency also causes a desquamative dry dermatosis, as well as retarded growth. A scaly dermatosis with increased skin permeability, depigmentation, fatty lung, and fatty liver was documented in EFA-deficient animals (2). Naismith (27) suggested that EFA deficiency occurs in kwashiorkor. He showed that the weaning foods of children with kwashiorkor in Nigeria contained less than minimum recommended intake of linoleic acid $(<1 \%$ of total energy intake). Plasmic linoleic and arachidonic acid levels were decreased, whereas the concentration of eicosatrienoic acid, an abnormal fatty acid, was increased; thus satisfying Holman's criterion for EFA deficiency (an eicosatrienoic to arachidonic acid ratio of $>0.4)(16,17)$. Other studies on children with kwashiorkor also have reported a decrease in the ratio of unsaturated to saturated fats in plasma $(22,35)$ and in red cell lipids (32).

Previous studies evaluated EFAs in kwashiorkor only. In the present study, a broader spectrum of malnutrition was studied in order to understand the peculiar features of kwashiorkor. Plasma lipids reflect changes in diet over a few days. Red cell lipids were measured because they reflect changes in lipid concentration and diet over a few weeks (11). Red cell lipids should 
not be sensitive to the acute crisis that resulted in hospital admission or to effects of treatment during the first wk of hospitalization. The present study correlated the presence of edema, dermatosis, hair changes, and hypoalbuminemia with the fatty acid composition of plasma and red cell lipids. Children with kwashiorkor exhibited changes in fatty acid composition similar to those seen in children with acrodermatitis enteropathica and biotin deficiency.

\section{MATERIALS AND METHODS}

Subjects. We studied forty-four children with third degree malnutrition (weight less than $60 \%$ of ideal weight for age) in three hospitals in Lima, Peru. Their average weight, height, and head circumference were $52 \%, 84 \%$, and $94 \%$, respectively, of the ideal for age, based on the Boston standard. They ranged in age from 1-27 mo (average $12 \mathrm{mo}$ ) and were hospitalized an average of $4 \mathrm{~d}$ before blood collection.

A single observer (J. Wolff) examined all children. He scored the physical findings of dermatosis, hair changes, and edema on a scale of 0 to 3:0 for no abnormality, 1 for slight, 2 for moderate, and 3 for marked change. Hepatomegaly was considered present when the liver span (measured by percussion and palpation) was greater than $9 \mathrm{~cm}$.

The majority of infants (92\%) had gastroenteritis with dehydration. A minority (18\%) also had pneumonia or sepsis. One marasmic child had keratomalacia but there was no evidence of specific nutritional deficiencies in other children. Seventy percent of the subjects were receiving intravenous fluids. In addition, $54 \%$ of the subjects had been offered a formula containing evaporated milk, ricewater, and sugar during the days of hospitalization before blood collection. Eleven children, who were totally recovered from third degree malnutrition, were the control subjects. We obtained blood from them after they had been hospitalized in the Instituto de Investigación Nutricional for over 2 mo.

Methods. Blood was collected at the time of physical examination by venipuncture into heparinized tubes containing one drop of a $0.1 \%$ butylhydroxy toluene solution. The whole blood was centrifuged at $2000 \mathrm{~g}$ for $15 \mathrm{~min}$. The packed cells were washed three times in five volumes of $0.89 \%$ saline. Lipids of the packed cells were extracted with isopropanol and methanol by the method of Rose and Oklander (31).

Plasma lipids were extracted by a modification of a method by Sperry and Brand $(23,38)$. Fatty acid methyl esters were prepared as decribed by Christie (5) by transesterification of the extracted lipids using a methanolic $\mathrm{HCl}$ reagent. Fatty acid methyl esters were partially purified by column chromatography over $6 \%$ hydrated $\mathrm{Al}_{2} \mathrm{O}_{3}$. Reference fatty acid methyl esters were purchased from Supelco, Inc.

Gas chromatographic analysis was done using a model $5700 \mathrm{~A}$ Hewlett-Packard Gas Chromatograph coupled to a HewlettPackard model 3385A Reporting Integrator. Two 6-ft stainless steel colums, $1 / 8$ in. outer diameter, packed with $15 \%$ ethylene glycol succinate coated on 100/120 mesh Gas-Chrom Q pretreated with $\mathrm{H}_{3} \mathrm{PO}_{4}$ were used. The carrier gas was $\mathrm{He}$ at a flow rate of $30 \mathrm{ml} / \mathrm{min}$. Standard mixes and samples were autoinjected. Initial oven temperature of $140^{\circ} \mathrm{C}$ was held for $16 \mathrm{~min}$ after injection, then heated at a rate of $1^{\circ} \mathrm{C} / \mathrm{min}$ to a final temperature of $200^{\circ} \mathrm{C}$. Upper temperature was maintained for $32 \mathrm{~min}$ before recycling. Detection was by dual differential FID with a $\mathrm{H}_{2}$ flow of $30 \mathrm{ml} / \mathrm{min}$ and air at $240 \mathrm{ml} / \mathrm{min}$. Detector and injector heated zones were $250^{\circ} \mathrm{C}$.

The plasma fatty acids measured are from the phospholipid, triglyceride, cholesterol ester, and free fatty acid pool. The red cell fatty acids are from the same pool in red cell membranes. Each fatty acid value was expressed as a percentage of the subject's total fatty acids.

Serum total protein and albumin concentrations were determined by the Biuret method and acetate gel electrophoresis.
Total and free cholesterol plasma concentration were measured with a BMC (Boehring-Mannheim Corp., Indianapolis, Indiana) kit, which utilizes an enzymatic colormetric assay (2).

\section{RESULTS}

Clinical findings. On the basis of the McLaren score, 22 children had marasmus, 11 had kwashiorkor and 11 had MK. The presence of hypoalbuminemia, dermatosis, edema, and hair changes correlated significantly in degree with each other and with the McLaren score (Table 1).

Cholesterol measurements. Compared with controls, plasma free cholesterol concentration was normal in marasmus but twice normal in kwashiorkor (Table 2). There was a negative correlation between plasma free cholesterol concentration and serum albumin.

These changes also were manifest in the altered ratio of cholesterol ester to free cholesterol. The ratio in both marasmus and MK was reduced from the control ratio of 2.52 to approximately 1.8. The ratio in kwashiorkor was reduced further to 0.87 . A significant positive correlation existed between serum albumin and the ratio of cholesterol ester to free cholesterol (Table 1).

Total plasma cholesterol concentration was normal in marasmus and MK and elevated in kwashiorkor, but not significantly. There was no correlation between total plasma cholesterol concentration and serum albumin.

Plasma fatty acids. Only one sample, plasma from an infant with marasmus, had any detectable eicosatrienoic acid (20:3 $\omega 9)$, but the ratio of $20: 3 \omega 9$ to $20: 4 \omega 6$ (arachidonic acid) was less than 0.4 . Holman's criterion for the diagnosis of EFA deficiency was not met.

Percentage linoleic acid ( $18: 2 \omega 6$ ) was one-third that of controls in all PCM children (Table 3). Percentage arachidonic acid (20:4 $\omega 6)$ was decreased only in kwashiorkor. The ratio of $18: 3 / 20: 3$ ( $\omega 6$ series) in the kwashiorkor group was twice as large as that in the control group or in the marasmus group. The ratio of 18:2/ $20: 4$ ( $\omega 6$ series) in the kwashiorkor group was also twice as large as in the marasmus group. There was a significant negative correlation between serum albumin and $20: 3$ and $20: 4$ of the $\omega 6$ series.

Red cell fatty acids. The red cell fatty acid results were similar to the plasma results. Eicosatrienoic acid $(20: 3 \omega 9)$ was not detected in any of the red cell samples. Serum albumin was correlated with most of the red cell percentage fatty acids (Table 4). The linoleic series' data were analyzed further because of the strong correlations between serum albumin and each of these four fatty acids (Table 5). Linoleic acid (18:2) in kwashiorkor was decreased from the control value of $15.3 \%$ to $10.9 \%$. In marasmus and MK, there were significantly greater decreases to $7.7 \%$ and $8.0 \%$, respectively. Arachidonic acid $(20: 4)$ in kwashiorkor was significantly $(P<0.001)$ decreased to $9.8 \%$ (control value, $13.1 \%$ ) whereas in marasmus there was no significant change. There was also a significant difference between percentage arachidonic acid values in marasmus and kwashiorkor $(P<$ 0.001 ). The percentage $20: 3$ intermediate was significantly decreased in all PCM children, but significantly more so in kwashiorkor than in marasmus or MK $(P<0.005)$. There was no change in the percentage $18: 3$ values. Serum albumin was negatively correlated with percentage linoleic acid $(P<0.001)$ and positively correlated with percentage $20: 3$ and arachidonic acid $(P<0.005)$.

The ratio of linoleic to arachidonic acid (18:2/20:4) was normal in kwashiorkor but was significantly decreased in $\mathrm{MK}$ and marasmus. The ratio of $18: 2 / 18: 3$ was decreased in all PCM children whereas the ratio of $20: 3 / 20: 4$ was decreased significantly only in kwashiorkor and MK. The ratio of 18:3/20:3 was doubled in kwashiorkor and similar to controls in marasmus. There was a significant negative correlation between serum albumin and 18:2/20:4, 18:2/18:3, and 18:3/20:3 and significant correlation with $20: 3 / 20: 4$. 
Table 1. Correlation* among physical and laboratory findings $\dagger$ for all children with protein-calorie malnutrition

\begin{tabular}{|c|c|c|c|c|c|c|c|c|c|c|c|}
\hline & MS & $\mathrm{HC}$ & $\mathrm{HE}$ & $\mathrm{ED}$ & $\mathrm{DE}$ & $\mathrm{AB}$ & $\mathrm{FC}$ & $\mathrm{TC}$ & $E / F$ & LA & AA \\
\hline \multirow[t]{2}{*}{ MS } & $\ldots$ & 0.36 & 0.15 & 0.89 & 0.84 & -0.80 & -0.65 & 0.22 & -0.48 & 0.54 & 0.45 \\
\hline & & II & $N S^{2}$ & I & I & II & I & NS & IV & IV & III \\
\hline \multirow[t]{2}{*}{$\mathrm{HC}$} & 0.36 & $\ldots$ & -0.04 & 0.30 & 0.36 & -0.40 & 0.34 & 0.14 & -0.25 & 0.43 & -.31 \\
\hline & II & & NS & I & I & II & I & NS & NS & III & 1 \\
\hline \multirow[t]{2}{*}{$\mathrm{HE}$} & 0.15 & 0.04 & $\ldots$ & 0.13 & 0.26 & 0.08 & 0.09 & 0.19 & -0.04 & -0.06 & -.08 \\
\hline & NS & NS & & NS & NS & NS & NS & NS & NS & NS & NS \\
\hline \multirow[t]{2}{*}{ ED } & 0.89 & 0.31 & 0.13 & $\ldots$ & 0.74 & -0.77 & 0.56 & 0.20 & 0.45 & 0.50 & -.36 \\
\hline & IV & I & NS & & IV & IV & IV & NS & III & IV & I \\
\hline \multirow[t]{2}{*}{$\mathrm{DE}$} & 0.84 & 0.36 & 0.26 & 0.74 & $\ldots$ & 0.63 & 0.53 & 0.16 & -0.38 & 0.48 & -.44 \\
\hline & IV & I & NS & IV & & IV & IV & NS & II & III & III \\
\hline \multirow[t]{2}{*}{$A B$} & -0.80 & -0.40 & 0.08 & -0.77 & -0.63 & $\ldots$ & -0.53 & -0.01 & 0.56 & 0.63 & 0.50 \\
\hline & IV & I & NS & IV & IV & & IV & NS & IV & IV & IV \\
\hline \multirow[t]{2}{*}{$\mathrm{FC}$} & 0.65 & 0.34 & 0.09 & 0.56 & 0.53 & -0.53 & $\ldots$ & 0.63 & -0.59 & 0.63 & -.29 \\
\hline & IV & I & NS & IV & IV & IV & & IV & IV & IV & NS \\
\hline \multirow[t]{2}{*}{ TC } & 0.22 & 0.14 & 0.19 & 0.20 & 0.16 & -0.01 & 0.63 & $\ldots$ & 0.16 & 0.26 & -.34 \\
\hline & NS & NS & NS & NS & NS & NS & IV & & NS & NS & I \\
\hline \multirow[t]{2}{*}{$\mathrm{E} / \mathrm{F}$} & -0.48 & -0.25 & -0.04 & -0.45 & -0.38 & 0.56 & -0.59 & 0.16 & $\ldots$ & 0.06 & 0.48 \\
\hline & IV & NS & NS & III & II & IV & IV & NS & & NS & IV \\
\hline \multirow[t]{2}{*}{ LA } & 0.54 & 0.43 & 0.06 & 0.50 & 0.48 & -0.63 & 0.63 & 0.26 & 0.06 & $\ldots$ & -.60 \\
\hline & IV & III & NS & IV & III & IV & IV & NS & NS & & IV \\
\hline \multirow[t]{2}{*}{$\mathrm{AA}$} & -0.45 & -0.31 & -0.08 & -0.36 & -0.44 & 0.50 & -0.29 & 0.34 & 0.48 & -0.60 & $\ldots$ \\
\hline & III & I & NS & I & III & IV & NS & I & IV & IV & \\
\hline
\end{tabular}

* NS, not significant. I, $P<0.05$, II, $P<0.01, \mathrm{III}, P<0.005$, and IV, $P<0.001$.

† Abbreviations: MS, McLaren score; HC, hair changes; HE, hepatomegaly; ED, edema; DE, dermatosis; AB, albumin; FC, free plasma cholesterol concentration; TC, total plasma cholesterol concentration; E/F, cholesterol ester/free cholesterol ratio; LA, percentage red cell linoleic acid; and AA, percentage red cell arachidonic acid.

Table 2. Plasma cholesterol concentrations $(m g / d l)$

\begin{tabular}{lccc} 
& $\begin{array}{c}\text { Controls } \\
(n=11)\end{array}$ & $\begin{array}{c}\text { Kwashiorkor } \\
(n=11)\end{array}$ & $\begin{array}{c}\text { Marasmus } \\
(n=22)\end{array}$ \\
\hline Free cholesterol & $30 \pm 10$ & $67 \pm 16$ & $40 \pm 8$ \\
Total cholesterol & $105 \pm 32$ & $128 \pm 52$ & $39 \pm 15$ \\
CE/FC ratio* & $2.52 \pm 0.55$ & $0.87 \pm 0.51$ & $97 \pm 22$ \\
\hline
\end{tabular}

* The means of the ratios of cholesterol ester to free cholesterol (CE/FC) were obtained by averaging the ratios for individual subjects.

Table 3. Percentage plasma fatty acids of the linoleic series ( $\omega 6)$

\begin{tabular}{lcccc}
$\begin{array}{c}\text { Fatty } \\
\text { acid }\end{array}$ & $\begin{array}{c}\text { Control } \\
(n=11)\end{array}$ & $\begin{array}{c}\text { Kwashiorkor } \\
(n=30)\end{array}$ & $\begin{array}{c}\text { Marasmus } \\
(n=17)\end{array}$ & $\begin{array}{c}\text { Marasmic } \\
\text { kwasiorkor } \\
(n=10)\end{array}$ \\
\hline $18: 2$ & $43.7 \pm 6.6$ & $16.6 \pm 4.3$ & $14.4 \pm 4.5$ & $14.5 \pm 5.9$ \\
$18: 3$ & $1.4 \pm 0.6$ & $1.0 \pm 0.3$ & $1.1 \pm 0.5$ & $1.0 \pm 0.5$ \\
$20: 3$ & $1.3 \pm 1.0$ & $0.6 \pm 0.3$ & $1.1 \pm 0.8$ & $0.7 \pm 0.3$ \\
$20: 4$ & $3.5 \pm 1.6$ & $2.7 \pm 0.7$ & $4.3 \pm 1.7$ & $3.7 \pm 1.4$ \\
$18: 2 / 20: 4^{*}$ & 12.5 & 6.1 & 3.3 & 3.9 \\
\hline
\end{tabular}

* The ratio was calculated by dividing the means obtained for each group.

Plasma and $R B C$ fatty acid correlations. Percentage plasma oleic, linoleic, and arachidonic acid values were significantly correlated $(r=0.8, P<0.001)$ with their respective red cell values. The ratio of red cell to plasma values for linoleic and arachidonic acid was significantly correlated with serum albumin.

\section{DISCUSSION}

Children with both kwashiorkor and marasmus had a significant decrease in red cell and plasma linoleic acid concentrations. This presumably is due to decreased dietary intake of linoleic acid compounded by fat malabsorption $(28,40)$; however, despite the higher concentration of linoleic acid in the kwashiorkor group, the concentration of arachidonic acid was significantly lower than the levels in the marasmus group or the control group. This resulted in a linoleic/arachidonic acid ratio (in red cells) of 0.67 in marasmus and 1.29 in kwashiorkor. There was a significant negative correlation in percentage arachidonic acid compared with the McLaren score, its associative findings, and percentage linoleic acid. Percentage linoleic acid was positively correlated with the McLaren score. Despite decreased linoleic acid in our children with kwashiorkor and marasmus, the abnormal eicosatrienoic acid was not present, which is contrary to Naismith's finding in Africa (27).

These findings of decreased arachidonic acid without eicosatrienoic acid have been reported in children with acrodermatitis enteropathica (an inherited form of zinc deficiency), in biotindeficient rats, and in a 12-mo-old child with documented biotin deficiency secondary to parenteral alimentation and short-gut syndrome $(4,23,24,26)$. Both the child with biotin deficiency and children with acrodermatitis enteropathica had a scaly dermatosis and alopecia, all common findings in kwashiorkor. Although normal levels of zinc have been found in the hair of children with kwashiorkor, hair zinc concentration may be an unreliable indicator of zinc status (36). Recent studies of Golden and Golden suggest that malnourished children may indeed be 
zinc depleted (14). The reason for the similar abnormal pattern of plasma fatty acid composition in kwashiorkor and acrodermatitis enteropathica remains unclear. It is not known if any of the enzymes involved in fatty acid metabolism are zinc dependent. An hypothesis for how biotin deficiency can cause abnormal fatty acid composition is explained below.

The differences in levels of linoleic acid and arachidonic acid between kwashiorkor and marasmus patients could be explained by alterations in the synthesis or breakdown of these fatty acids. It is not known whether the catabolism of certain unsaturated fats are specifically and differentially affected by dietary or hormonal changes $(8,41)$. The influence of dietary and hormonal changes on the synthesis of unsaturated fatty acids has been studied in animals. The major pathway of conversion of linoleic acid to arachidonic acid occurs in three steps: $I$ ) desaturation to 18:3,2) elongation to $20: 3$, and 3) desaturation to $20: 4$ (Fig. 1) (13). Desaturation of fatty acids is decreased by increased blood sugar, glucagon, epinephrine, lack of insulin, cyclic AMP, and fasting. It is increased by protein intake $(3,8,9)$.

Table 4. Correlations of red cell percentage fatty acids with serum albumin

\begin{tabular}{cc}
\multicolumn{2}{c}{ serum albumin } \\
\hline Red cell fatty acids* & $\begin{array}{c}\text { Correlations with } \\
\text { serum albumin }\end{array}$ \\
\hline $16: 0$ & $-0.16(\mathrm{NS}) \dagger$ \\
$16: 1 \omega 7+$ & $-0.55(\mathrm{IV})$ \\
$18: 0$ & $0.38(\mathrm{I})$ \\
$18: 1 \omega 9$ & $0.09(\mathrm{NS})$ \\
$18: 2 \omega 6$ & $-0.59(\mathrm{IV})$ \\
$18: 3 \omega 6$ & $0.15(\mathrm{NS})$ \\
$20: 0$ & $0.72(\mathrm{III})$ \\
$20: 3 \omega 6$ & $0.52(\mathrm{III})$ \\
$20: 4 \omega 6$ & $0.46(\mathrm{III})$ \\
$22: 1 \omega 9$ & $0.05(\mathrm{NS})$ \\
$22: 6 \omega 7$ & $0.11(\mathrm{NS})$ \\
$24: 0$ & $0.57(\mathrm{IV})$ \\
$24: 1 \omega 9$ & $0.10(\mathrm{NS})$
\end{tabular}

Ratios for the linoleic $(\omega 6)$ series $^{*}$

$\begin{array}{cc}18: 2 / 20: 4 & -0.49(\mathrm{III}) \\ 18: 2 / 18: 3 & -0.49(\mathrm{I}) \\ 18: 3 / 20: 3 & -0.4(\mathrm{I}) \\ 20: 3 / 20: 4 & 0.41(\mathrm{I})\end{array}$

* These were all the red cell fatty acids measured (besides $20: 3 \omega 9$ ).

$\dagger$ NS, not significant. I, $P<0.05$, II, $P<0.01$, III, $P<0.005$, IV, $P<$ 0.001 .

$\ddagger \omega$ notation indicates the position of the first double bond numbered from the methyl terminus.

These ratios were calculated by averaging the ratios for individual subjects.
Assuming no significant differences in the catabolism or utilization of these fatty acids, the pattern in kwashiorkor of decreased $18: 2 / 18: 3$ and 20:3/20:4 and increased 18:3/20:3 ratio is consistent with either an increased rate of desaturation or a decreased rate of elongation, or both. Because desaturation is decreased, not increased, in the fasting state, decreased elongation seems likely $(8,12)$. Elongation occurs mainly in microsomes, where it requires malonyl $\mathrm{CoA}$; a minor pathway for elongation occurs in mitochondria and utilizes acetyl $\mathrm{CoA}$. Biotin is required for the production of malonyl $\mathrm{CoA}$ and is thus required for the major pathway of elongation $(24,39,41)$. Perhaps children with kwashiorkor differ from those with marasmus by having some form of biotin deficiency. This hypothesis of impaired elongation could be proved by in vivo measurement of elongation using labeled compounds or by tissue studies in vitro.

A pure deficiency in linoleic acid is accompanied by an increase in eicosatrienoic acid $(20: 3 \omega 9)$. It is thought that in the nondeficient state, linoleic acid competitively inhibits conversion of oleic to eicosatrienoic acid because of linoleic acid's greater affinity for the desaturating and elongating enzymes it shares with oleic acid. With decreased linoleic acid, the naturally produced oleic acid is converted to the abnormal eicosatrienoic acid (Fig. 1) (13). Children with EFA deficiency have decreased linoleic and arachidonic acid, and increased eicosatrienoic acid. Children with kwashiorkor, acrodermatitis enteropathica, or biotin deficiency have decreased linoleic and arachidonic acid and no eicosatrienoic acid. Children with marasmus have decreased linoleic acid, normal arachidonic acid, and no eicosatrienoic acid. Decreased elongation would explain the absence of eicosatrienoic acid in kwashiorkor, but not in marasmus. Most likely, different enzyme systems of desaturation and elongation exist for the three different EFA series and are affected differently by metabolic disturbances (39).

The decrease in arachidonic acid and 20:3 $\omega 6$ in kwashiorkor might explain some of its signs. Both are precursors of prostaglandins (7). In particular, the dermatosis in EFA deficiency is the result of altered epidermal prostaglandins due to a decrease in its precursors, $20: 3 \omega 6$ and arachidonic acid $(22,31,32)$. Also, eicosatrienoic acid $(\omega 9)$ inhibits prostaglandin synthesis and the interconversion of prostaglandins $(43,45,46)$. The significantly decreased 20:3 $\omega 6$ and arachidonic acid levels in kwashiorkor might also alter epidermal prostaglandins, causing a dermatosis. The dermatosis in kwashiorkor could be different from that in EFA deficiency because of the absence of eicosatrienoic acid in kwashiorkor. Altered prostaglandins also affect melanocyte function and the formation of edema and could contribute to the changes in pigmentation and edema in kwashiorkor $(34,44)$. Altered prostaglandins might also explain the possible zinc depletion in kwashiorkor because prostaglandin $E_{2}$ assists zinc absorption in rats (37). The role that prostaglandins play in the pathogenesis of kwashiorkor, acrodermatitis enteropathica, and biotin deficiency remains to be determined.

Table 5. Percentage red cell fatty acids of the linoleic ( $\omega 6)$ series

\begin{tabular}{|c|c|c|c|c|}
\hline $\begin{array}{l}\text { Fatty } \\
\text { acids }\end{array}$ & Controls & Kwashiorkor & Marasmus & Marasmic kwashiorkor \\
\hline $18: 2$ & $15.3 \pm 1.9(11)^{*}$ & $10.9 \pm 2.0(13)$ & $7.7 \pm 2.2(19)$ & $8.0 \pm 2.8(10)$ \\
\hline $18: 3$ & $0.7 \pm 0.1(8)$ & $0.7 \pm 0.1(11)$ & $0.7 \pm 0.1(10)$ & $0.7 \pm 0.2(5)$ \\
\hline $20: 3$ & $1.7 \pm 0.6(11)$ & $0.8 \pm 0.4(11)$ & $1.3 \pm 0.3(14)$ & $1.0 \pm 0.4(8)$ \\
\hline $20: 4$ & $13.1 \pm 1.7(11)$ & $9.8 \pm 2.6(13)$ & $12.2 \pm 1.9(19)$ & $11.3 \pm 2.4(10)$ \\
\hline \multicolumn{5}{|l|}{ Ratios $\dagger$} \\
\hline $18: 2 / 20: 4$ & $1.19 \pm 0.24(11)$ & $1.26 \pm 0.79(13)$ & $0.67 \pm 0.31(19)$ & $0.78 \pm 0.41(10)$ \\
\hline $18: 2 / 18: 3$ & $22.9 \pm 3.7(8)$ & $16.4 \pm 5.5(11)$ & $10.7 \pm 5.5(10)$ & $10.8 \pm 6.0(5)$ \\
\hline $18: 3 / 20: 3$ & $0.52 \pm 0.31(8)$ & $1.10 \pm 0.61(10)$ & $0.68 \pm 0.18(10)$ & $1.00 \pm 0.40(5)$ \\
\hline $20: 3 / 20: 4$ & $0.13 \pm 0.05(11)$ & $0.08 \pm 0.03(11)$ & $0.11 \pm 0.03(14)$ & $0.09 \pm 0.04(8)$ \\
\hline
\end{tabular}

* Number of subjects in sample.

$\uparrow$ Ratios were obtained by averaging the ratios calculated for individual sujects. 


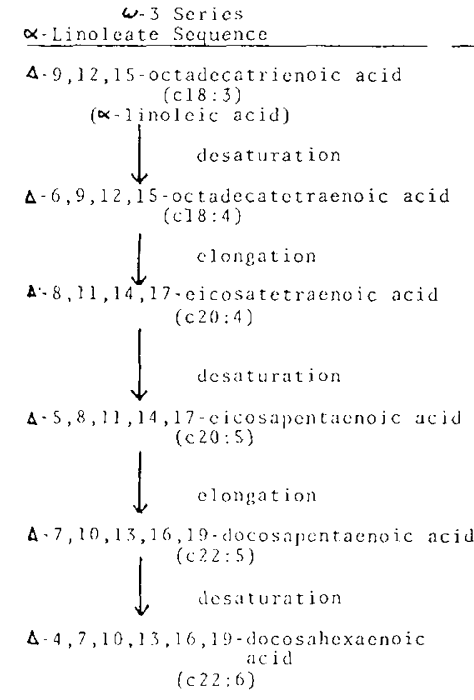

$(c 22 ; 6)$

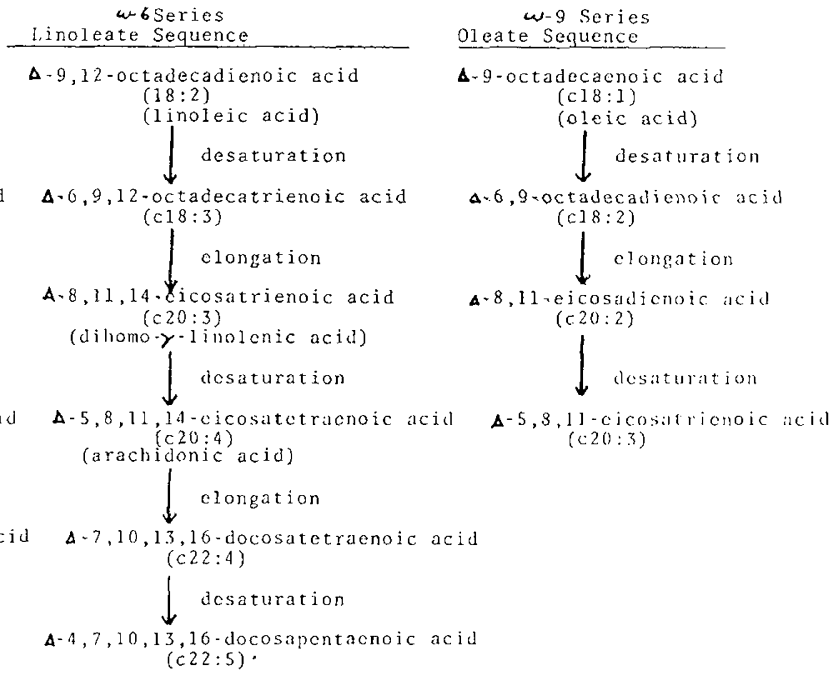

Fig. 1.

\section{REFERENCES AND NOTES}

1. Allain. C. C: Enzymatic determination of total serum cholesterol. Clin. Chem., 20): $470(1974)$.

2. Bernick, S. and Alfin-Slater. R. B.: Pulmonary infiltration of lipid in essential fatty-acid deficiency. Arch. Pathol., 75: 13 (1963).

3. Brenner, R.: The desaturation step in the animal biosynthesis of polyunsaturated fatty acids. Lipids, 6: 567 (1971).

4. Cash. R. and Berger. C. K.: Acrodermatitis enteropathica: defective metabolism of unsaturated fatty acids. J. Pediatr. 74: 717 (1969).

5. Christie, W. W.: Lipid Analysis. p. 88 (Pergamon Press Inc., Elmsford. NY. 1976).

6. Coward. W. A. and Whitehead, R. G.: Changes in serum B-lipoprotein concentration during the development of kwashiorkor and in recovery. $\mathrm{Br} . \mathrm{J}$. Nutr.. 27: 383 (1972).

7. Danon. A.. Heimberg. M. and Oates. J. A.: Enrichment of rat tissue lipids with fatty acids that are prostaglandin precursors. Biochim. Biophys. Acta. 388: 318 (1975).

8. DeGomez Dumm, I. N. T., de Alaniz, M. J. T., and Brenner, R.: Effect of diet on linoleic acid desaturation and on some enzymes of carbohydrate metabolism. J. Lipid Res., 11: 96 (1970).

9. DeGomez Dumm, 1. N. T. de Alaniz. M. J. T.. and Brenner, R. R.: Comparative effect of glucagon, dibutyryl cyclic AMP. and epinephrine on the desaturation and clongation of linoleic acid by rat liver microsomes. Lipids. 11: 833 (1976).

10. DuPont. J. and Mathias, M.: Bio-oxidation of linoleic acid via methylmalonylCoA. Lipids, 4: 478 (1969).

11. Farquhar, J. W. and Ahrens, E. H.: Effects of dietary fats on human erythrocyte fatty acid patterns. J. Clin. Invest. 42: 675 (1963).

12. Friedman. Z.. Danon. A.. Stahlman. M. T. and Oates, J. A.: Rapid onset of essential fatty acid deficiency in the new born. Pediatrics, 5: 640 (1976).

13. Friedman. $Z:$ Polyunsaturated fatty acids in the low-birth-weight infant. Semin. Perinatol. 3: 341 (1979).

14. Golden. M. H. N. and Golden, B. E.: Effect of zinc supplementation on the dictary intake. rate of weight gain. and energy cost of tissue deposition in children recovering from severe malnutrition. Amer. J. Clin. Nutr., 34: 900 (1981).

15. Gurson. C. T.. Kurdoglu, G.. and Saner, G.: Serum total lipids and lipid fractions in marasmus. Nutr. Metabol.. 15: 181 (1973).

16. Hansen, A. E., Wiese. H. F., Boelsche. A. N., Haggard, M. E., Adam, D. J. D. and Davis. H.: Role of linoleic acid in infant nutrition. Pediatrics, 31:171 (1963).

17. Holman. R. T.. Caster, W. O., and Wiese, H. F.: The essential fatty acid requirement of infants and the assessment of their dietary intake of linoleate by serum fatty acid analysis. Amer. J. Clin. Nutr.. 14:70 (1964).

18. Jaya Rao, K. S. and Krishna Prasad, P. S.: Serum triglycerides and nonesterfied fatty acids in kwashiorkor. Amer. J. Clin. Nutr.. 19:205 (1966).

19. Lewis, B. Hansen, J. D. L.. Wittman. W.. Krut. L. H.. and Stewart. F.: Plasma free fatty acids in kwashiorkor and the pathogenesis of the fatty liver. Amer. J. Clin. Nutr., 15: 161 (1964).

20. Lowe. N. J.: Essential fatty acid deficient hairless mouse: the effects of topical agents on the epidermis. Brit. J. Derm.. 97: 39 (1977).

21. Lynen, $F$ : The role of biotin-dependent carboxylations in biosynthetic reactions. Biochem. J.. 10? 381 (1967)

22. MacDonald, 1.. Jansen. J. D. L.. and Bronte-Stewart. B.: Liver. depot and serum lipids during early recovery from kwashiorkor. Clin. Sci., 24: 55 (1963).

23. Marshall, Mary: Personal Communication. (Lipid Laboratory, U. S. Dept.
Agriculture Beltsville MD 20705).

24. Marshall. M.. Haubrich. M., and Mason, B.: Lipids in Red Blood cells of mature hypercholesterolemic rats in relation to sex and biotin status. Nutr. Rep. Int., 13: 389 (1976)

25. McLaren, D. S. Pellett, P. L and Read W W C. A simple scoring system for classifying the scvere forms of protein-caloric malnutrition of early childhood. Lancet, 1:533 (1967).

26. Mock. D. M.. DeLorimer, A. A., Sweetman. L., and Baker, H.: Biotin deficiency: An unusual complication of parenteral alimentation. N. Eng. J. Med.. 304: $820(1981)$.

27. Naismith, D. J.: Kwashiorkor in western Nigeria: a study of traditional weaning foods. with particular reference to energy and linoleic acid. Br. J. Nutr. 30. 567 (1973).

28. Infantile malnutrition and malabsorption. Nutr. Rev.. 31: 321 (1973).

29. Essential fatty acids and water permeability of the skin. Nutr. Rev., 35: 303 (1977).

30. Prottey, C.: Investigation of functions of essential fatty acids in the skin. Br. J. Derm. 97: 29 (1977).

31. Rose, H. G. and Iklander, M.: Improved procedure for the extraction of lipids from human erythrocytes. J. Lipid Res.. 6:428 (1965).

32. Sakr. R. El-Hawary, M. F. S.. Samuel, S. and Hiskial, N.: Total lipids fatty acids percent composition in plasma and RBC's in protein-caloric malnutrition (P.C.M.) in U.A.R. Gazette of the Egyptian Pediatric Association. 19: $61(1971)$.

33. Sauk, J. J., White, J. G., and Witkop. C. J.: Influence ofy prostaglandins E1. E2 and arachidonate on melanosomes in melanocytes and keratinocytes of anagen hair bulk in vitro. J. Invest. Derm. 64.332 (1975).

34. Schendel, H. D. and Hansen, J. D. L.: Studies on fat metabolism in Kwashiorkor: serum polyunsaturated fatty acids. Am. J. Clin. Nutr. 9: 735 (1961)

35. Schwartz. R. and Dean. R. F. A.: The serum lipids in Kwashiorkor. J. Trop. Pediatr. 3: 23 (1957)

36. SooHoo, T. Bradfield, R.. Baertl. J.: Effect of hypochromotrichia on hair copper and zinc during Kwashiorkor. Am. J. Clin. Nutr.. 34: 1315 (1981).

37. Song. M. K. and Adham. N. F.: Role of prostaglandin E2 in zinc absorption in the rat. Am. J. Physiol., 234: E99(1978).

38. Sperry. W. M. and Brand, F. C.: The determination of total lipids in blood serum. J. Biol. Chem., 213: 69(1955).

39. Sprecher. $H_{\text {.: }}$ The influence of dietary alterations, fasting and competitive interactions on the microsomal chain elongation of fatty acids. Biochim. Biophys. Acta, 360: 113 (1974)

40. Teotia, M. Teotia, S. P. S., Sharma, N. L., and Kunwart. K. B.: Fat absorption studies in Kwashiorkor. Indian J. Med. Res. 60:620 (1972).

41. Travis, S.. Mathias. M., and DuPont, J.: Effect of biotin deficiency on the catabolism of linoleate in the rat. J. Nutr., I02: 767 (1972).

42. Truswell, A. S., Hansen. J. D. L.. Watson, C. E., and Wannenburg. P.: Relation of serum lipids and lipoproteins to fatty liver in Kwashiorkor. Am. J. Clin. Nutr. 22: 568 (1969).

43. Van Evert, W. C. Nugteren, D. H.. and Van Dorp. D. A.: Inhibition of prostaglandin biosynthesis by $c-5, c-8, c-11$-eicosatrienoic acid. Prostaglandins. 15: 267 (1978)

44. Williams. T. H. and Peck, M. J.: Role of prostaglandin mediated vasodilatation in inflammation. Nature, 270:530 (1977)

45. Ziboh, V. A Lord, J T and Penneys, N. S. Alterations of prostaglandins E2-9-ketoreductase activity in proliferating skin. J. Lipid Res., 18:37 (1977).

46. Ziboh. V. A.. Vanderhoek. J. Y.. and Lands, W. E. M.: Inhibition of sheep vesicular gland oxygenase by unsaturated fatty acids from skin of essential fatty acid-deficient rats. Prostaglandins, 5: 233 (1974).

47. Requests for reprints should be addressed to: Jon A. Wolff, M.D., Department 
of Pediatrics. University of California, San Diego, Medical Center. 225 Dickinson Strect. San Dicgo, California 91203

48. The authors are grateful to Dr. Augustin Gongora for his generous cooperation in obtaining the subjects' blood samples and to Dr. Ron Riggio for his help with the statistical analyses. This research was supported in part by a grant from the National Institutes of Health. HD 10111 and a contract with the
Agency for International Development. Department of State ta-C-1286.

49. This research was supported in part by a grant from the National Institutes of Health. HD 10111 and a contract with the Agency for International Development. Department of State, ta-C-1286.

50 Received for publication June $21,1982$.

51. Accepted for publication April 13,1983.

\title{
Complementation, Cross Correction, and Drug Correction Studies of Combined $\beta$-Galactosidase Neuraminidase Deficiency in Human Fibroblasts
}

\author{
PIETRO STRISCIUGLIO, KIM E. CREEK. AND WILLIAM S. SLY ${ }^{(17)}$ \\ The Edward Mallinckrodt Department of Pediatrics, Washington University School of Medicine, Division of \\ Medical Genetics, St. Louis Children's Hospital, St. Loulis, Missouri USA
}

\begin{abstract}
Summary
Neuraminidase activity in fibroblasts obtained from a patient with combined $\beta$-galactosidase-neuraminidase deficiency $(\beta$ $\mathrm{gal}^{-} /$neur') was partially restored by fusion with two ML I cell lines and an ML II cell line. As observed with neuraminidase activity, $\beta$-galactosidase also showed complementation with an increase in activity when $\beta$-gal ${ }^{-} /$neur $^{-}$fibroblasts were fused with an ML II or a $G_{M I}$ gangliosidosis cell line. Both $G_{M !}$ gangliosidosis and sialidosis fibroblasts secreted a "corrective factor" which, when added to medium above $\beta$-gal $/$ neur $^{-}$fibroblasts, was pinocytosed and partially corrected its deficiencies for these two enzymes. This partial correction of $\beta$-galactosidase and neuraminidase activities persisted for at least $72 \mathrm{~h}$ after removal of the "corrective factor" from the medium. A "corrective factor" with similar properties was obtained from glycoproteins isolated by chromatography of human spleen homogenates on concanavalin A-Sepharose. Treatment of $\beta$-gal $/ /$ neur $^{-}$fibroblasts with leupeptin or EP475, two inhibitors of lysosomal thiolproteases, partially restored $\beta$-galactosidase activity but caused no significant improvement in neuraminidase levels. The partial corrective effect of leupeptin on $\beta$-galactosidase activity persisted for at least $\mathbf{2} \mathbf{d}$ after removal of the drug, even in the presence of cycloheximide.
\end{abstract}

\section{Abbreviation}

$\beta$-gal ${ }^{-} /$neur ${ }^{-}, \beta$-galactosidase-neuraminidase deficiency

In the past few years, a defect in acid neuraminidase (sialidase) activity has been demonstrated in several disorders presenting various clinical phenotypes. Neuraminidase deficiency has also been demonstrated in another group of patients originally found to have a $\beta$-galactosidase deficiency $(14,16)$. In these cases the neuraminidase deficiency was inferred to be the primary metabolic block responsible for the $\beta$-galactosidase deficiency since $\beta$ galactosidase levels in the parents of affected patients were generally not reduced. Complementation analysis between cell lines obtained from patients deficient in both $\beta$-galactosidase and neuraminidase $\left(\beta\right.$-gal ${ }^{-} /$neur $\left.^{-}\right)$with those from patients affected only by neuraminidase deficiency (ML I) have been reported by two laboratories but with differing conclusions $(9,10)$. Using a heterokaryon enrichment procedure, Mueller and Shows (13) recently presented convincing evidence of restoration of neuraminidase activity after fusion of ML I fibroblasts with those from $\beta$-gal ${ }^{-} /$neur ${ }^{-}$. Furthermore, Hoogeveen et al. (8) showed that the combined deficiency of $\beta-\mathrm{gal}^{-} /$neur ${ }^{-}$in human fibroblasts in culture can be partially corrected by the addition of concentrated culture medium collected from several mutant lines of human fibroblasts, including those with isolated $\beta$-galactosidase $\left(\mathrm{G}_{\mathrm{M}}\right.$ gangliosidosis) or neuraminidase (ML I) deficiency. Similar corrective effects were observed by these authors by treating $\beta-\mathrm{gal}^{-} /$neur ${ }^{-}$fibroblasts with the protease inhibitor leupeptin (5). Suzuki et al. (15) were able to confirm this corrective effect with leupeptin for $\beta$-galactosidase but not neuraminidase.

In order to help clarify the metabolic defect responsible for the combined $\beta-\mathrm{gal}^{-} /$neur ${ }^{-}$deficiency we have conducted complementation, cross correction, and drug correction studies on fibroblasts obtained from a patient with the infantile form of combined $\beta$-gal ${ }^{-} /$neur $^{-}$that we have followed for the past $8 \mathrm{yr}$ (1). These studies provided additional support for the proposal recently made by d'Azzo et al. (3) that the combined $\beta$-gal ${ }^{-/}$ neur- deficiency is not due to a defect in the structural gene for $\beta$-galactosidase or neuraminidase, but rather in a glycoprotein which is normally required to protect these two enzymes against intralysosomal degradation.

\section{MATERIALS AND METHODS}

Materials. Sialyllactose was purchased from Sigma Chemical Co., St. Louis, MO. Most 4-methylumbelliferyl substrates were obtained from Research Products International Corp., Elk Grove Village, IL except the 4-methylumbelliferyl substrate for neuraminidase was from Kock-Light as was the polyethylene glycol (molecular weight 1000). Concanavalin A-Sepharose was from Pharmacia. Leupeptin and EP-475 were generous gifts from Dr. A. L. Goldberg, Dept. Physiology, Harvard Medical School, Boston, MA. Human spleens were obtained from the Dept. of 